\title{
Health-Related Quality of Life in Portuguese Children and Adolescents
}

\author{
Qualidade de Vida Relacionada à Saúde de Crianças \\ e Adolescentes Portugueses
}

\author{
Margarida Gaspar de Matos", ${ }^{*}$, Tania Gaspar $^{b}, \&$ Celeste Simões ${ }^{a}$ \\ ${ }^{a}$ Universidade Técnica de Lisboa, Lisboa, Portugal \& ${ }^{b}$ Universidade Lusíada, Lisboa, Portugal
}

\begin{abstract}
The KIDSCREEN is a European cross-cultural and standardized instrument that assesses ten quality of life dimensions in children, adolescents and their parents. This instrument is used to validate evidences to support general inferences on quality-of-life measures obtained by the Portuguese version of KIDSCREEN10 for children and adolescents, in the context of a survey research carried on in Portugal. The present study focuses only on the KIDSCREEN children and adolescents' versions. A sample of 8072 Portuguese children and adolescents attending the $5^{\text {th }}$ grade $(19.3 \%), 6^{\text {th }}$ grade $(19.2 \%), 7^{\text {th }}$ grade $(20.3 \%), 8^{\text {th }}(21.6 \%)$ and $10^{\text {th }}$ grade $(19.7 \%)$ in Portuguese schools were inquired, with a mean age of $13.2 ; S D 2.06$, randomly distributed regarding gender. The Portuguese version of KIDSCREEN-10 instrument showed a good Internal Consistency of .78. Chosen fit indexes indicate good fit to the data. Specifically in the final solution the RMSEA was lower than .03 and the upper limit of $90 \%$ confidence interval was lower than .05 , and CFI was higher than .95. Results indicated that the current 10-item structure is invariant across age groups, nationality and socio-economic level. The KIDSCREEN-10 questionnaire is a reliable instrument to estimate the perception of quality of life in children and adolescents. Psychometric guidelines are presented for the Portuguese population aged 10 to 16 years old.

Keywords: Assessment, health-related quality of life, children and adolescents.

\section{Resumo}

O KIDSCREEN é um instrumento europeu transcultural e padronizado que avalia dez dimensões da qualidade de vida de crianças, adolescentes e seus pais. Este instrumento é usado para validar evidências a fim de apoiar inferências gerais sobre medidas de qualidade de vida obtidas pela versão portuguesa do KIDSCREEN-10 para crianças e adolescentes, no contexto de uma pesquisa de investigação feita em Portugal. O presente estudo centra-se apenas na versão KIDSCREEN para adolescentes e crianças. Uma amostra de 8.072 crianças e adolescentes portugueses frequentando a $5^{\mathrm{a}}$ série $(19,3 \%), 6^{\mathrm{a}}$ série $(19,2 \%), 7^{\mathrm{a}}$ série $(20,3 \%), 8^{a}$ série $(21,6 \%)$ e $10^{a}$ série $(19,7 \%)$ em escolas do país foram intrevistadas, com uma idade média de 13,2; DP 2,06, distribuídos aleatoriamente em relação ao sexo. A versão portuguesa do instrumento KIDSCREEN-10 mostrou uma boa consistência interna de 0,78 . Os índices de ajuste escolhidos indicam bom ajuste aos dados. Especificamente na solução final o RMSEA foi inferior a 0,03, o limite superior do intervalo de confiança de $90 \%$ foi inferior a 0,05 e CFI foi superior a 0,95 . Resultados indicaram que a estrutura atual do item 10 é invariável entre grupos de idade, nacionalidade e nível socio-econômico. $\mathrm{O}$ questionário KIDSCREEN-10 é um instrumento confiável para estimar a percepção da qualidade de vida em crianças e adolescentes. Orientações psicométricas são apresentadas para a população portuguesa entre 10 e 16 anos de idade.

Palavras-chave: Avaliação, qualidade de vida relacionada à saúde, crianças e adolescentes.
\end{abstract}

Children and adolescents have been recognized as important facets of global public health. Adopting an approach linked to the quality of life can increase the

\footnotetext{
* The authors acknowledge the European Kidscreen Group for technical and scientific guidance and the Project Aventura Social Team for collaboration in data collection and analysis.

Address: Faculdade de Motricidade Humana, Projecto Aventura Social, Universidade Técnica de Lisboa, Estrada da Costa, Cruz Quebrada, 1499 Lisboa codex, Portugal. E-mail: mmatos@fmh.utl.pt
}

understanding and knowledge of the health of children and adolescents and help to establish policies that promote their health and well-being (Fuh, Wang, Lu, \& Juang, 2005).

Measuring the health-related quality of life has a growing importance as an over time mean of monitoring the health of the population, to detect subgroups of the population with lower HRQoL (Health Related Quality of Life) and evaluating the impact of interventions on public health in a given population. Before the project 
KIDSCREEN there were no standardized cross-cultural relevant instruments for application with equivalence in paediatric populations in different European populations from different countries (Rajmil et al., 2004; RavensSieberer et al., 2001; Ravens-Sieberer et al., 2005). Apart from that, the subjective health has been considered of utmost importance to consider the state of health in national samples in international studies and regarding the measurement of perceptual indicators of health, namely the collaborative study of the World Health Organization (WHO), Health Behaviour in School Aged Children ([HBSC], Currie, Hurrelmann, Settertobulte, Smith, \& Todd, 2000; Currie et al., 2004; Currie, Samdal, Boyce, \& Smith, 2001; Matos et al., 2000, 2003; Matos et al., 2006; Ravens-Sieberer et al., 2009).

There are new models considering quality of life not only as a functional matter or life status but also as a construct that involves a psychosocial adjustment, well-being, self-esteem, stress and coping, these five factors emphasize the world's self-perception of children and adolescents, their preferences and the quality of their world according to them, including the perception of personal happiness (Harding, 2001). If children or adolescents present more protective factors, they will assess their quality of life as the highest. The protective factor may mediate the relationship between the characteristics and skills of children and adolescents and therefore their quality of life (Gaspar, 2010; Lawford \& Eiser, 2001).

Health Related Quality of Life (HRQoL) it is influenced by several personal factors, such us, self-esteem and optimism and social factors such us, relations with family and peer group (Gaspar, Matos, Ribeiro, Leal, \& Ferreira, 2009). Some studies associate the perception of well-being and personal happiness to having less risk behaviours and more protective health ones (Currie et al., 2008; Currie et al., 2000; Currie et al., 2004; Currie et al., 2001; Matos et al., 2003; Matos et al., 2006).

Rajmil et al. (2004) claimed that the concept of healthrelated quality of life in children and adolescents is not clearly defined, they underwent a literature review on generic and specific instruments for measuring the quality of life related to health, pointing out differences between definitions: the domains were almost always the same but they were distinctly operationalized. In the initial phase of the KIDSCREEN project development - that meant to create a new European instrument for measuring the health-related quality of life in children and adolescents - the authors argued that all questionnaires should include items from physical, psychological and social domains but the distribution of the number of items varied considerably between areas (Ravens-Sieberer et al., 2001).

The project's objective is not only for KIDSCREEN to develop an instrument to measure HRQoL for children, adolescents and their parents, but also to describe the relationships between the questionnaire and other relevant KIDSCREEN determinants. The KIDCSREEN group carried on an in depth literature review pointing out in addition to demographic variables (gender, age and SES), also other relevant determinants such as the physical and mental health of children and adolescents, and their relationship with parents, health status (physical, mental and social) and parental and social support. The HRQoL is correlated to health behaviours of children and adolescents and their use of health services. The assumptions for the construction of the relationship between HRQoL and the determinants were based on an integrative model proposed by The KIDSCREEN Group Europe (Detmar et al., 2006). This approach to a multidimensional quality of life provides information on different aspects of health-related quality of life providing a structure to identify and develop strategies to promote HRQoL in children and adolescents (Helseth \& Lund, 2005).

The promotion of health requires the active support of physical and mental well-being and social health of individuals. The prevention of health is not only related to factors that may threat health and welfare, but also to preventive interventions based on measuring the health of children and adolescents at all levels. The health or subjective perceptions of well-being are considered important aspects of health promotion and are relevant indicators in the area of public health (Detmar et al., 2006; Ravens-Sieberer et al., 2001)

KIDSCREEN-52 was developed within the European project "Screening and Promotion for Health-Related Quality of Life in Children and Adolescents - A European Public Health Perspective" (European Commission). During 3 years (2001-2004), 13 countries were co-ordinated by the German team (Rajmil et al., 2004; RavensSieberer et al., 2001) who developed and evaluated this instrument, presenting a version for children and a version for parents, which can be used with children from 8 to 18 years old and their parents. It is a self-reported questionnaire of 52 items, which requires about 15 minutes being filled and reports to the "passed week". The KIDSCREEN52 is organized in 10 dimensions: Physical Well-being (5 items), Psychological Well-being (6 items), Moods and Emotions (7 items), Self-Perception (5 items), Autonomy (5 items), Parent Relation and Home Life Context (6 items), Financial Resources (3 items), Social Support and Peers (6 items), School Environment (6 items) and Social Acceptance and Bullying. The original scale was developed in English.

From the KIDSCREEN-52 Instrument were developed two short versions, KIDSCREEN-27 with 27 items, organized in 5 dimensions and KIDSCREEN-10 one-dimensional scale with ten items. The rational of short versions was to provide professionals both with an in depth instrument for clinical and research purposes, and to provide short versions for screening proposes, in school or hospital settings or as a moderator variable regarding population studies. Short versions were carried on by means of narrowing of the scope conceptually followed by subsequent 
exploratory factor analysis and confirmatory factor analysis, and were published elsewhere (Gaspar et al., 2010a; Matos \& Gaspar, 2006; Ravens-Sieberer et al., 2001). KIDSCREEN-10 short version consisted of only one general factor (Global health related quality of life) while the long 52 item consisted of 10 sub scales estimating several aspects of HROL, and the 27 item consisted of 5 subscales, as said.

The long version was the first version translated (using standard methods of double translation, back translation and between judges agreement), and validated in Portugal and the results where already published elsewhere, together with a detailed procedure of translation and back translation, which were not necessary for the short version because the items are the same, only less (Gaspar et al., 2010a). Regarding the long 53 item version the individual factors related with feelings and emotions and family context were the variables that influenced more Gaspar, Matos, Batista-Foguet, Ribeiro and Leal (2010). Fur-thermore, could be found gender, age and socioeconomic differences. Boys tended to present a higher HRQoL in almost all dimensions, except in relation with school environment where girls revealed higher HRQoL. Children present a higher HRQoL in almost all dimensions, except related with financial resources and provocation, where adolescents showed higher HRQoL. Children and adolescents with lower socio-economic status (SES) presented lower HRQoL than students with higher SES (Gaspar et al., 2010b). Parents and their children have different perception of children and adolescents HRQoL. Parents are more optimistic than their children in relation to areas such us, emotions, self-esteem, autonomy and family context. Children and more positive in relation to financial resources and peer group than parents reported (Gaspar et al., 2010). There is a version available in Portuguese from Brazil (see Brazilian team member at www.kidscren.org )

The main objective of this paper was to get valid evidences to support general inferences on quality-of-life measures obtained by the Portuguese version of KIDSCREEN-10 for Portuguese children and adolescents, in the context of a survey research carried on in Portugal, and to provide psychometric guidelines for this age population.

\section{Method}

\section{Sample}

Sampling methods were derived from the international study "Health Behaviour School Aged-Children" (HBSC/ WHO). The HBSC/WHO study's sample (Matos et al., 2006) was enlarged, and two extra random classes $\left(5^{\text {th }}\right.$ grade and $7^{\text {th }}$ grade) were selected in each of the national randomly selected schools where $6^{\text {th }}, 8^{\text {th }}$ and $10^{\text {th }}$ grade were targeted for the purpose of HBSC study.

Schools were stratified by National Educational Regions (5 in the whole country), following HBSC/WHO (for further details about sampling procedures, see Currie et al., 2001; Matos et al., 2003; Matos et al., 2006, or www.hbsc.org). The present study is thus a cross sectional national study, representative of Portuguese public schools (not including Portuguese islands), and provides a random national representative sample of pupils attending $5^{\text {th }}$, 6 th, 7 th, 8 th and $10^{\text {th }}$ grade, extracted randomly from the national list of schools provided by the Ministry of Education.

KIDSCREEN questionnaires were applied in a classroom setting. Questionnaires were anonymous and answered in a voluntarily bases. The research project was submitted and approved by several national organizations (Ministry of Education, National Data Protection Commission, and Ethics Commission) and the parents' informed consent was requested.

The study involved 135 schools and 301 classes. A sample of 8072 children and adolescents, both genders, that attended the $5^{\text {th }}$ grade $(19 \%), 6^{\text {th }}$ grade $(19.2 \%), 7^{\text {th }}$ grade $(20.3 \%), 8^{\text {th }}(21.6 \%)$ and $10^{\text {th }}$ grade $(19.7 \%)$ was inquired, the students had a mean age of 13.2 years old; $S D 2.06$ (10 to less than 12 years old $-29.2 \%$; 12 to less than 13 years old $-36.8 \%$; 14 years old or older $34.1 \%$ ). Parents were included in the main study (Matos \& Gaspar, 2006) but parents' data was not included in this paper.

\section{Instrument}

For the development of the KIDSCREEN-10 Index, items were derived from longer version, in a previous work that encompassed both theoretical and statistics aspects described elsewhere (Ravens-Sieberer et al., 2001). The good internal consistency (Cronback's alpha $=.82$ ) and the good test-retest reability/stability $(r=.73 ; \mathrm{ICC}=.72)$ enable a precise and stable HRQoL measurement. The KIDSCREEN-10 is able to differentiate groups; low scores can be read as feeling unhappy, unfit and dissatisfied regarding the family life, peers and school life, high scores indicate the opposite, feeling happy, fit and satisfied with family, school and peers group. The instrument result in one global score, that one-dimensional measure represents a global score adequate for use in large (epidemiological) surveys (The KIDSCREEN Group Europe, 2006; RavensSieberer et al., 2001).According to international guidelines, the translation of the KIDSCREEN draft questionnaire included a forward-backward-forward translation procedure with harmonisation processes, which were done during the KIDSCREEN 52 validation (Gaspar et al., 2010a; Matos \& Gaspar, 2006)

\section{Statistical Procedures}

A confirmatory factor analysis (CFA) was run with 8072 participants to confirm the 10 items factor structure of KIDSCREEN-10. Factorial invariance across, age group (younger/older), nationality (Portuguese/non Portuguese) and socioeconomic status (SES) (low/medium/high) was analyzed. In addition to chi-square, alternative fit indexes such as the comparative fit index (CFI), non-normed fit 
index (NNFI), root mean square error of approximation (RMSEA), standardized root mean squared residual (SRMR) are also presented. The procedures used to determine factorial invariance included: (a) verification of configural invariance, in which the equivalence of the specified structure of factor loading is tested for each paired-groups (unconstrained model); (b) verification of metric invariance, in which the model is also tested in combination for each paired-group, but free or estimated factor loadings are restricted to test the equivalence of the two samples - constrained model (in the present study, only the factorial invariance of the factor loadings is tested. Nevertheless, it is possible to test the invariance of other free or estimated parameters, such as correlation between factors, variances or covariances between error measurements, and residuals - disturbances; Byrne, 1994). Simulation studies show that the difference in CFI between the model with and without restrictions is among the most adequate measures to assume factorial invariance (Cheung \& Rensvold, 2000). Therefore, a difference equal or lower than .01 in CFI represents a good indicator of factorial invariance.

\section{Results}

KIDSCREEN-10 instrument analysis regarding the psychometric properties showed a good internal consistency (Alpha Cronbach's $=.78$ ). This value does not become higher if one of the 10 items is deleted. The purpose of this paper was to determine the factorial structure of the Portuguese version of KIDSCREEN-10 items in children and adolescents, and to verify factorial invariance across diverse sample groups.

\section{Confirmatory Factor Analysis}

A confirmatory factor analysis (CFA) was conducted on 8072 participants. The goodness-of-fit estimates reported correspond to the robust solution (except for SRMR). In addition, the Satorra-Bentler Chi-square ( $\mathrm{Hu}$ \& Bentler, 1999) and fit indexes that control non-normality results were used. The fit indices held in the analysis for the model were indicative of an ill-fitting model (Satorra-Bentler $\chi^{2}=3057.54$ (35), $P<.001 ; \mathrm{CFI}=.758$; NNFI=.688; RMSEA=.107; SRMR=.071), Good models have an CFI and NNFI of .95 or more and an RMSEA and SRMR of .05 or less (Bentler, 1995; Hu \& Bentler, 1999). Nevertheless, LM test showed that if some parameters, in this case error covariances, were freely estimated the $\chi^{2}$ would drop significantly. These parameters were the error covariances between the following items (that reported to the "passed week"): "Did you did well at school? / Were you able to pay attention during classes?"; "Have you felt sad? / Have you felt lonely?"; "Have you felt fit and well? / Have you felt full of energy?" Since the content of the items is associated and the result of the first analysis shows a large drop in $\chi^{2}$ value, these parameters were free up in the model one by one. The results of these specifications in the model are shown in Table 1.

Table 1

Fit Indexes of the Initial Model and the Model with the Introduction of Parameters (error covariances)

\begin{tabular}{lccccc}
\hline \multicolumn{1}{c}{$\chi^{2}(d f)^{\mathrm{a}}$} & $\mathrm{CFI}^{\mathrm{b}}$ & $\mathrm{NNFI}^{\mathrm{b}}$ & RMSEA $\left(90 \%\right.$ C.I $^{\mathrm{b}}$ & SRMR \\
\hline Initial Model & $3057.54^{* * *}(35)$ & .758 & .688 & $.107(.104-.110)$ & .071 \\
Step 1 & $1882.26^{* * *}(34)$ & .852 & .804 & $.085(.082-.088)$ & .053 \\
Step 2 & $1021.28^{* * *}(33)$ & .921 & .892 & $.063(.060-.066)$ & .040 \\
Step 3 & $408.44^{* * *}(32)$ & .970 & .958 & $.039(.036-.043)$ & .028 \\
\hline
\end{tabular}

Note. Satorra-Bentler $\chi^{2}=, P<.001 ; \mathrm{CFI}=. ; \mathrm{NNFI}=. ; \mathrm{RMSEA}=. ; \mathrm{SRMR}=.071^{\text {a }}$.

${ }^{\mathrm{a}}$ Satorra-Bentler; ${ }^{\mathrm{b}}$ Robust.

$* p<.05 ; * * p<.01 ; * * * p<.001$.

Step 1 - Introduction of the error covariances between the items "Did you did well at school?/Were you able to pay attention during classes?"

Step 1 - Introduction of the error covariances between the items "Have you felt sad?/ Have you felt lonely?"

Step 1 - Introduction of the error covariances between the items "Have you felt fit and well?/ Have you felt full of energy?"

As it is possible to see, the $\chi^{2}$ value had a large drop in each of the steps related to the introduction of error covariances in the model (free estimation). In the last step the $\chi^{2}$ value [Satorra-Bentler $\chi^{2}=408.44$ (32), $P<.001$ ], although significant, which is often observed with large sample sizes (Cheung \& Rensvold, 2002; Schumacker \& Lomax, 1996), is much lower than in first analysis. Also the CFI and the other fit indexes had shown an important improve for each step and especially in the final step $(\mathrm{CFI}=.970 ; \mathrm{NNFI}=.958$; RMSEA=.039; $\mathrm{SRMR}=.028)$.

The Wald tests confirmed that all parameters included in the initial model are significant and, therefore, were maintained. Figure 1 presents the factor loadings of the final model. 


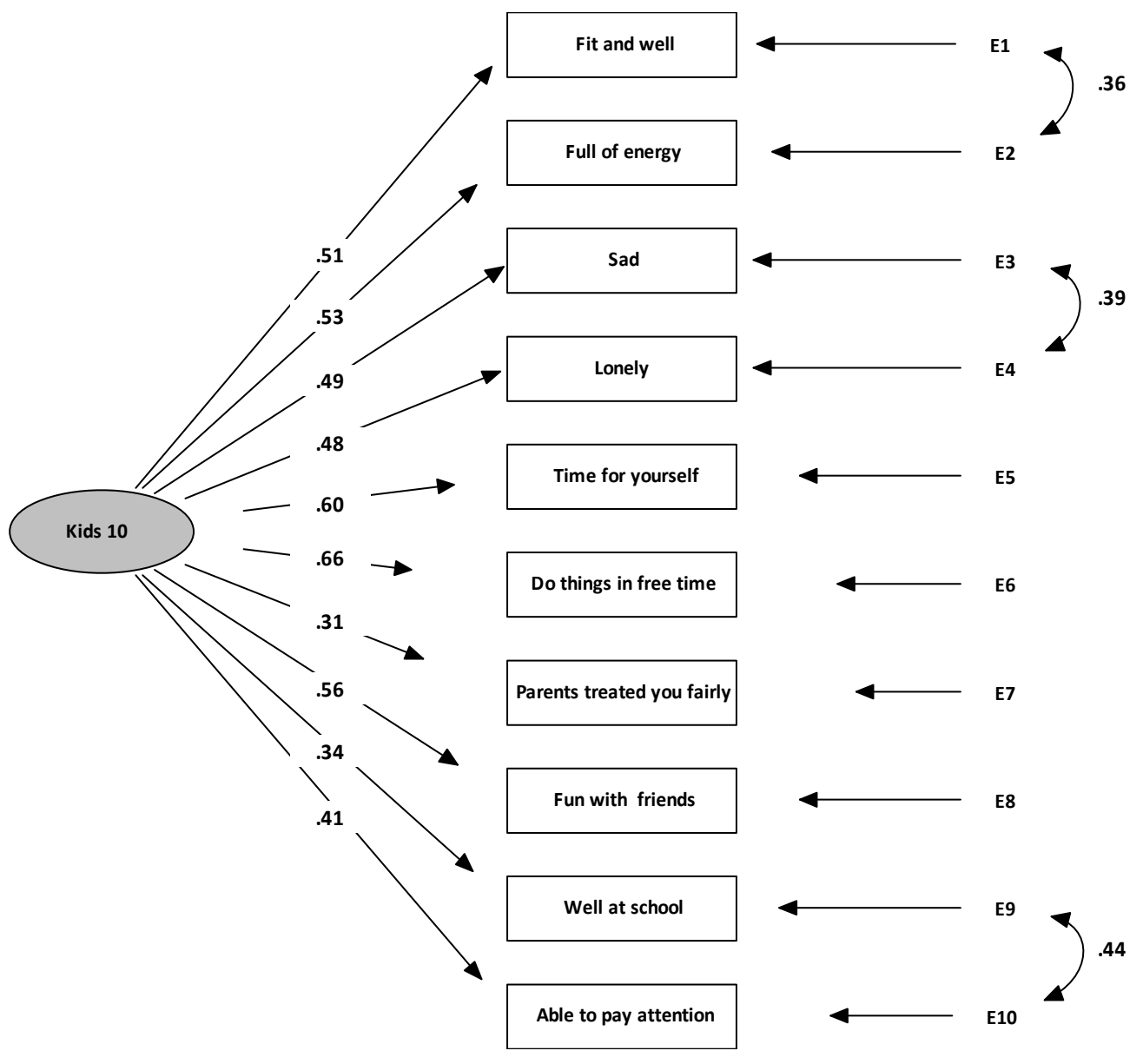

Figure 1. Final model of the Portuguese version of KIDSCREEN-10.

Factorial Invariance

To determine the factorial invariance of the 10-item KIDSCREEN, comparisons across groups were conducted. The variables in study were: (a) age group (Younger group: Mean age $=11.30 ; S D=.82$; Min $=10.00$; $\operatorname{Max}$ $=12.99$ and / Older group: Mean age $=14.71 ; S D=1.39$;
Min=13.00; $\operatorname{Max}=19.92)-$ younger $(n=3646) v s$. older ( $n=4426)$; (b) nationality - Portuguese $(n=7416) v s$. non Portuguese $(n=540)$; (c) socioeconomic status - low ( $n=3916) v s$. medium/high $(n=1917)$.

Results for factorial invariance are summarized in Table 2 , where adjustment indexes for both unconstrained and constrained models are shown.

Table 2

Factorial Invariance with Fit Statistics for Unconstrained and Constrained Models

\begin{tabular}{lcccc}
\hline & $\mathrm{CFI}^{\mathrm{a}}$ & $\chi^{2}(d f)^{\mathrm{b}}$ & $\chi^{2} / d f$ & RMSEA $(90 \% \mathrm{CI})^{\mathrm{a}}$ \\
\hline $\begin{array}{l}\text { Younger - Older } \\
\quad \text { Unrestricted }\end{array}$ & .969 & $434.65^{* * *}(64)$ & 6.79 & $.040(.037-.044)$ \\
$\quad$ Restricted & .967 & $469.83^{* * *}(73)$ & 6.44 & $.039(.035-.042)$ \\
$\quad \begin{array}{l}\text { Portuguese - non Portuguese } \\
\quad \text { Unrestricted }\end{array}$ & .968 & $296.61^{* * *}(64)$ & 4.63 & $.041(.037-.046)$ \\
$\quad$ Restricted & .967 & $315.37^{* * *}(73)$ & 4.32 & $.039(.035-.044)$ \\
$\quad$ Low SES - Medium/High SES & & & & \\
$\quad$ Unrestricted & .972 & $316.67^{* * *}(64)$ & 4.95 & $.038(.034-.042)$ \\
$\quad$ Restricted & .971 & $328.83^{* * *}(73)$ & 4.50 & $.036(.032-.040)$ \\
\hline
\end{tabular}

${ }^{\mathrm{a}}$ Robust; ${ }^{\mathrm{b}}$ Satorra-Bentler Chi-Square.

$* p<.05 ; * * p<.01 ; * * * p<.001$. 
Matos, M. G., Gaspar, T. \& Simões, C. (2012). Health-Related Quality of Life in Portuguese Children and Adolescents.

The factorial structure of the questionnaire was confirmed for the unconstrained models since it presents adequate fit indexes (CFI and RMSEA) in each of the paired groups. Metric invariance is also observed as CFI difference between unconstrained and constrained models is smaller than .01 in all paired groups. Table 3 represents factor loadings and explained variances of each item for all groups.

Table 3

Invariance Testing: Factor Loadings $(\lambda)$ and Explained Variance $\left(R^{2}\right)$ for all 10 KIDCREEN Items

\begin{tabular}{|c|c|c|c|c|c|c|c|c|c|c|c|c|}
\hline \multirow{3}{*}{$\begin{array}{l}\text { Factor } \\
\text { Items }\end{array}$} & \multicolumn{4}{|c|}{ Age Group } & \multicolumn{4}{|c|}{ Nationality } & \multicolumn{4}{|c|}{ SES } \\
\hline & \multicolumn{2}{|c|}{ Younger } & \multicolumn{2}{|c|}{ Older } & \multicolumn{2}{|c|}{ Portuguese } & \multicolumn{2}{|c|}{ Non Portuguese } & \multicolumn{2}{|c|}{ Low } & \multicolumn{2}{|c|}{ Medium/High } \\
\hline & $\lambda$ & $R^{2}$ & $\lambda$ & $R^{2}$ & $\lambda$ & $R^{2}$ & $\lambda$ & $R^{2}$ & $\lambda$ & $R^{2}$ & $\lambda$ & $R^{2}$ \\
\hline Fit and well & .456 & .208 & .559 & .312 & .549 & .301 & .483 & .233 & .496 & .246 & .512 & .262 \\
\hline Full of energy & .516 & .266 & .559 & .312 & .581 & .338 & .500 & .250 & .551 & .304 & .522 & .273 \\
\hline Sad & .507 & .257 & .473 & .224 & .454 & .206 & .569 & .323 & .491 & .241 & .486 & .236 \\
\hline Lonely & .515 & .265 & .458 & .210 & .465 & .216 & .494 & .244 & .511 & .262 & .464 & .216 \\
\hline Time for yourself & .608 & .370 & .588 & .346 & .573 & .329 & .607 & .369 & .644 & .414 & .582 & .339 \\
\hline Do things in free time & .654 & .428 & .656 & .431 & .649 & .421 & .663 & .440 & .656 & .430 & .636 & .405 \\
\hline Parents treat you fairly & .299 & .089 & .315 & .099 & .311 & .096 & .357 & .127 & .292 & .085 & .333 & .111 \\
\hline Fun with friends & .563 & .317 & .567 & .322 & .554 & .307 & .612 & .375 & .556 & .309 & .541 & .293 \\
\hline Well at school & .358 & .128 & .334 & .112 & .333 & .111 & .393 & .154 & .316 & .100 & .328 & .108 \\
\hline Able to pay attention & .424 & .179 & .413 & .171 & .404 & .163 & .365 & .133 & .403 & .162 & .406 & .165 \\
\hline
\end{tabular}

Although the first solution of the confirmatory factor analysis showed an inadequate fit of the model, the search for non fitting parameters, namely error covariances, and its introduction in model, conducted to a significant improvement of the model and to a solution where this 10 -item one-factor structure is supported. The introduction of these error covariances is justified because the unique components of these indicators are sharing something which is outside and of no interest to the model. Even though Satorra-Bentler $\chi^{2}$ was significant, and the ratio $\chi^{2} / d f$ was much higher than the recommended value of between 2 and 3 for indication of good fit (Carmines \& McIver, 1981), or 5 (Kline, 2005), these results are not surprising as it has been shown that fit indexes based on chi-square are over sensitive to sample size (Cheung \& Rensvold, 2002; Schumacker \& Lomax, 1996). In addition, this index is also sensitive to assumptions of violation of multivariate normality (Byrne, 2001). Chosen fit indexes indicate good fit to the data. Specifically, in the final solution, the RMSEA was lower than .03 and the upper limit of $90 \%$ confidence interval was lower than .05, and CFI was higher than .95 .

Results indicate that the current 10 -item structure is invariant across age groups, nationality and SES. Even though $\chi^{2}$ was significant while comparing unconstrained and constrained models and the $\chi^{2} / d f$ ratio is higher than the cut off value, this can be attributed to the large sample size (Schumacker \& Lomax, 1996). As a consequence of the inflation of chi-square measures due to sample size, Meade, Johnson and Braddy (2006) recommended that researchers should rely more heavily on alternative fit indexes to analyze measurement invariance. The CFI for both models was very high (above .96) and changes were bellow .01 (Cheung \& Rensvold, 2002) which suggests that differences between the constrained and unconstrained models are minimal.

The results suggested that the measurement construct generalizes across groups and that KIDSCREEN was measured and interpreted similarly across groups. Because the factor structure was consistent across a variety of samples, it is thought that the present version can be used confidently by researchers in analyzing and interpreting scores of KIDSCREEN across a variety of samples in Portuguese children and adolescents, and that this instrument can be used in cross-cultural research. For this purpose are included (Table 4) the means and the SD and the percentiles, for the total sample, and three age group corresponding to early adolescence (younger than 12), adolescence (12-13 years old) and late adolescence (older than 14 years old). As seen, people in the younger group fall less frequently in the category "very low QOL", and people in the older group fall less frequently in the category "high QOL". However, regarding the "very high QOL” age group is no different.

\section{Discussion}

The KIDSCREEN-10 instrument has several strengths. It is based on a cross-cultural sensitive concept and available in many European countries, including Portugal. It is appropriate for use in multinational collaborative research.

The instrument is able to be used in research involving several interventions, as well for applications in many 
Table 4

Descriptive for the Whole Sample (Mean, SD and percentiles) and by Age Group

\begin{tabular}{lcccc}
\hline & Total & $<12$ years .old & 12-13years .old & $>14$ years .old \\
\hline Mean & 73.2 & 73.3 & 73.3 & 72.9 \\
SD & 14.3 & & & \\
Percentile & & & & 55 \\
$\quad$ Very low QOL 10 & 55 & 52.5 & 55 & 65 \\
$\quad$ Low QOL25 & 65 & 65 & 65 & 75 \\
$\quad$ Average QOL 50 & 75 & 75 & 75 & 82.5 \\
$\quad$ High QOL75 & 82.5 & 85 & 85 & 90 \\
$\quad$ Very high QOL 90 & 90 & 90 & 90 & \\
\hline
\end{tabular}

health and educational settings; that also can be applied with equal relevance in healthy populations and paediatrics populations with specific health conditions.

These results indicate that overall, the KIDSCREEN10 is a sound, cross-cultural valid assessment of HRQOL for children and adolescents, as reflected by its conceptual and methodological strengths. KIDSCREEN-10 questionnaire is a reliable instrument to estimate the perception of quality of life in children and adolescents. It is adequate for use in large (epidemiological) surveys and as a complementary scale in studies related to children and adolescents' health behaviours and health conditions.

Monitoring the health of a population is a major research activity in public health therefore measuring the healthrelated quality of life has a growing importance detecting subgroups of the population with lower HRQoL (Health Related Quality of Life) and evaluating the impact of interventions on public health in given population.

Up to 2006 (Matos \& Gaspar, 2006) there was no standardized cross-cultural relevant instrument for application in paediatric populations in Portugal. The translation and validation of KIDSCREEN 52 provided clinicians and researchers with a validated Portuguese version that allowed not only establishing the state of art in Portugal, but also allowed for cross country comparisons (The KIDSCREEN Group Europe, 2006; Ravens-Sieberer et al., 2005).

Now the KIDSCREEN 10 provided not only clinicians and researchers but also general practitioners and researchers with a sound instrument to estimate HRQOL in children and adolescents. This new short version allows for policy monitoring and it is now nationally used within the HBSC /WHO national study, as a well being index (Currie et al., 2008; Ravens-Sieberer et al., 2009).

Next steps include validating both KIDSCREEN 52 and 10 for children and adolescents in paediatric settings, namely children and parents (using the parents' version already translated and validated in Portugal; Gaspar et al., 2010), focusing on families where children have a chronic health condition. Another next step is to use this index as a general monitoring system to feed policy makers (mainly in the Education and health field) with a valid index accounting for the evaluation of universal or selective interventions in schools. A final next step has to do with the extension of this work to other Portuguese speaking countries where it is intended to carry on locally, nationally appropriated versions, culturally validated, because, no matter if the language is the same, HRQOL, as a culturally embedded construct, calls for a specific cultural validation locally.

\section{References}

Bentler, P. M. (1995). EQS Structural Equations Program Manual. Encino, CA: Multivariate Software.

Byrne, B. M. (1994). Structural Equation Modeling with EQS and EQS/Windows: Basic concepts, applications and programming. Thousand Oaks, CA: Sage.

Byrne, B. M. (2001). Structural equation modeling with AMOS: Basic concepts, applications, and programming. Mahwah, NJ: Erlbaum.

Carmines, E., \& McIver, J. (1981). Social measurement: Current issues. In G. Bohrnstedt \& E. Borgatta (Eds.), Analyzing models with unobserved variables: Analysis of covariance structures (pp. 65-115): Beverly Hills, CA: Sage.

Cheung, G. W., \& Rensvold, R. B. (2000). Testing measurement invariance using critical values of fit indices: A Monte Carlo study. Retrieved February 20, 2004, from http://www.aom. pace.edu/rmd/cheung_files/cheung.htm

Cheung, G. W., \& Rensvold, R. B. (2002). Evaluating goodnessof-fit indexes for testing measurement invariance. Structural Equation Modeling, 9, 233-255.

Currie, C., Nic Gabhain, S., Godeau, E., Roberts, C., Smith, R., Currie, D., et al. (Eds.). (2008). Inequalities in young people's health: HBSC international report from the 2005/ 06 survey (Health Policy for Children and Adolescents, No. 5). Copenhagem, Denmark: World Health Organisation.

Currie, C., Hurrelmann, K., Settertobulte, W., Smith, R., \& Todd, J. (Eds.). (2000). Health and health behaviour among young people (Health Policy for Children and Adolescents, No. 1). Copenhagem, Denmark: World Health Organisation.

Currie, C., Roberts, C., Morgan, A., Smith, R., Settertobulle, W., Samdal, O., et al. (2004). Young people's health in context. Health Behaviour in School-aged Children study: International report from the 2001/2002 survey (Health Policy for Children and Adolescents, No. 4). Copenhagen, Denmark: World Health Organisation. 
Matos, M. G., Gaspar, T. \& Simões, C. (2012). Health-Related Quality of Life in Portuguese Children and Adolescents.

Currie, C., Samdal, O., Boyce, W., \& Smith, R. (2001). HBSC, a WHO cross national study: Research protocol for the 2001/ 2002 survey. Copenhagen, Denmark: World Health Organisation.

Detmar, S., Bruil, J., Ravens-Sieberer, U., Gosch, A., Bisegger, C., \& The European KIDSCREEN Group. (2006). The use of focus group in the development of the KIDSCREEN HRQL questionnaire. Quality of Life Research, 15(8), 1345-1353.

Fuh, J., Wang, S., Lu, S., \& Juang, K. (2005). Assessing quality of life for adolescents in Taiwan. Psychiatric and Clinical Neurosciences, 59, 11-18.

Gaspar, T. (2010). Health-related quality of life in children and adolescents: Personal and social factors that promote quality of life. Saarbrücken, Germany: Lambert Academic.

Gaspar, T., Matos, M., Batista-Foguet, Ribeiro, J., \& Leal, I. (2010). Parent-child perceptions of quality of life: Implications for health intervention. Journal of Family Studies, 16(2), 143-154

Gaspar, T., Matos, M., Ribeiro, J. L., Leal, I., Erhart, M., \& Ravens-Sieberer, U. (2010a). Kidscreen-52: Quality of life in children and adolescents. Journal of Children and Adolescents Psychology, 1, 49-64.

Gaspar, T., Matos, M., Ribeiro, J. L., Leal, I., Erhart, M., \& Ravens-Sieberer, U. (2010b). Kidscreen: Differences related to gender, age socio economic status and health status in Portuguese teens. Journal of Children and Adolescents Psychology, 2, 87-103.

Gaspar, T., Matos, M., Ribeiro, J., Leal, I.,. \& Ferreira, A. (2009). Health-related quality of life in children and adolescents and associated factors. Journal of Cognitive and Behavioral Psychotherapies, 9(1), 33-48.

Harding, L. (2001). Children's Quality of Life Assessments: A review of genetic and health related quality of life measures completed by children and adolescents. Clinical Psychology and Psychotherapy, 8, 79-96.

Helseth, S., \& Lund, T. (2005). Assessing health-related quality of life in adolescents: Some psychometric properties of the first Norwegian version of KINDL. Scandinavian Journal Caring science, 19, 102-109.

Hu, L., \& Bentler, P. (1999). Cuttoff criteria for fit indices in covariance structure analysis: Conventional criteria versus new alternatives. Structural Equation Modeling, 6, 1-55.

The KIDSCREEN Group Europe. (2006). The KIDSCREEN questionnaires: Quality of life questionnaires for children and adolescents. Lengerich, Germany: Pabst Science.

Kline, R. B. (2005). Principles and practice of structural equation modelling ( $2^{\text {nd }}$ ed.). New York: Guilford Press.

Lawford, J., \& Eiser, C. (2001). Exploring links between the concepts of quality of life and resilience. Pediatric Rehabilitation, 4(4), 209-216.

Matos, M. G., \& Gaspar, T. (2006). Qualidade de vida em crianças e adolescentes portugueses-Manual do Kidscreen. Retrieved from www.fmh.utl.pt/aventurasocial; www. aventurasocial.com

Matos, M. G., Gonçalves, A., Reis, C., Simões, C., Santos, D., Diniz, J. A., et al. (2000). A saúde dos adolescentes portugueses. Lisboa, Portugal: Universidade Técnica de Lisboa.

Matos, M. G., Gonçalves, A., Reis, C., Simões, C., Santos, D., Diniz, J. A., et al. (2003). A saúde dos adolescentes portugueses (quatro anos depois). Lisboa, Portugal: Universidade Técnica de Lisboa.
Matos, M. G., Simões, C., Tomé, G., Gaspar, T., Camacho, I., Diniz, J. A., et al. (2006). A saúde dos adolescentes portugueses - Hoje e em 8 anos - Relatório Preliminar do Estudo HBSC 2006. Retrieved from www.fmh.utl.pt/aventurasocial; www.aventurasocial.com

Meade, A. W., Johnson, E. C., \& Braddy, P. W. (2006, August). The utility of Alternative Fit Indices in Tests of Measurement Invariance. Paper presented at the annual Academy of Management Conference, Atlanta, GA. Retrieved from www4.ncsu.edu/ awmeade/Links/Papers/AFIsMI (AoM06).pdf

Rajmil, L., Herdman, M., Sanmamed, M., Detmar, S., Bruil, J., Ravens-Sieberer, U., et al. (2004). European Generic healthrelated quality of life instruments in children and adolescents: A qualitative analysis of content. Journal of Adolescent Health, 34, 37-45.

Ravens-Sieberer, U., Gosch, A., Abel, T., Auquier, P., Bellach, B., Bruil, J., et al. (2001). Quality of life in children and adolescents: A European public health perspective. Preventivmed, 46, 294-302.

Ravens-Sieberer, U., Gosch, A., Rajmil, L., Erhart, M., Bruil, J., Duer, W., et al. (2005). KIDSCREEN-52 quality-of-life measure for children and adolescents. Expert Review of Pharmacoeconomics \& Outcomes Research, 5(3), 353-364.

Ravens-Sieberer, U., Torsheim, T., Hetland, J., Vollebergh, W., Cavallo, F., Jericek, H., et al. (2009). Subjective health, symptom load and quality of life of children and adolescents in Europe. International Journal of Public Health, 54, 151159.

Schumacker, R. E., \& Lomax, R. G. (1996). A beginner's guide to structural equation modeling. New York: Lawrence Erlbaum. 